\title{
Rapid-Manufacturing-Process for Elastomeric Components
}

\author{
http://dx.doi.org/10.3991/ijes.v3i2.4593 \\ M. Launhardt, M. Drexler and D. Drummer \\ Friedrich-Alexander-Universität Erlangen-Nürnberg (FAU), Erlangen, Germany
}

\begin{abstract}
The Selective Laser Sintering Process of thermoplastics (SLS) enables the manufacturing of components with complex shape in a short time period without the manufacturing of a specific mold. However, this manufacturing process is limited by the restricted range of materials. In contrast to this primary shaping process, vacuum casting allows a quick, inexpensive and highly accurate process but it is limited to the reproduction of already existing models. In a novel rapid tooling method, these two processes are combined. Thus, silicone parts can be manufactured using SLS molds.
\end{abstract}

Design/methodology/approach - The manufacturing of elastomeric parts in the vacuum casting process using SLS molds is being investigated. Therefore, the adhesion of silicone to the SLS mold, as well as the resulting mechanical properties of the elastomeric parts are investigated.

Findings - The combination of the SLS process and the vacuum casting process allows the rapid manufacturing of complex elastomeric parts with sufficient mechanical properties.

Research limitations/implications - The surface roughness of the SLS mold influences the adhesion of the casting material to the mold, as well as the mechanical properties of the manufactured elastomeric components.

Originality/value - The synergy of using selective laser sintered molds with the vacuum casting technique displays a novel rapid manufacturing method.

Index Terms-adhesion, Rapid Manufacturing, RapidPrototyping, Selective Laser Sintering (SLS), silicone, vacuum casting.

\section{INTRODUCTION}

The selective Laser Sintering process with thermoplastics (SLS) was developed and patented by Dr. Carl Deckhard in 1989. It provides the possibility to manufacture complex shaped parts directly from CAD data in short time. In the process polymer powder is distributed layer wise and subsequently the two-dimensional part shape is melted using a CO-laser. After finishing one layer, the building platform lowers the height of one layer and the process repeats until the part is finished [1], Fig 1.

After the manufacturing and the subsequent cool down to room temperature, the parts can be extracted from the remaining powder. Usually a post process sand blasting is applied in order to remove leftover powder from the SLS parts $[2,3]$.

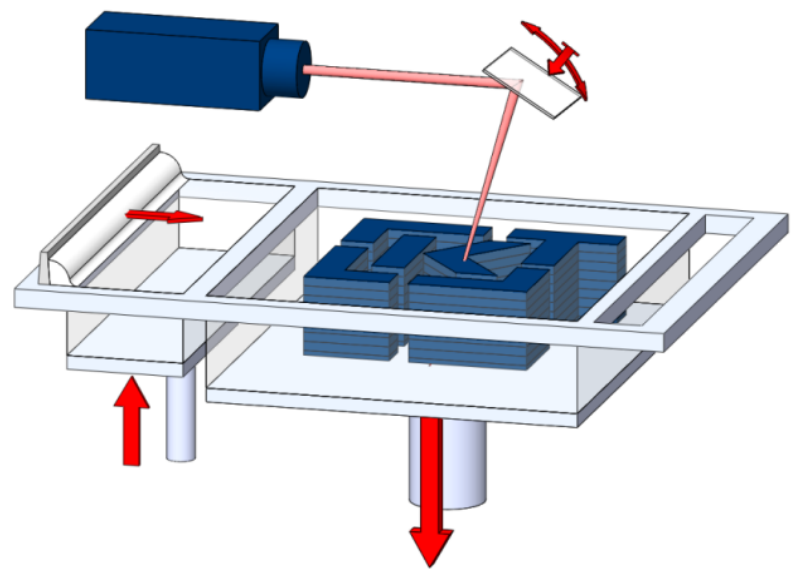

Figure 1. Schematic of the Selective Laser Sintering Process.

The Selective Laser Sintering process is limited on a small selection of thermoplastic and semicrystalline polymers, e. g. Polyamide 12 (PA12) [4]. However, some thermoplastic elastomers are available for the SLS process, such as TPU and Polyester based Elastomer [5, 6, 7, 8]. Though, these materials have not yet established in industry.

In general SLS parts are used for rapid prototyping reasons. Further, the coating of laser sintered PA12 parts with silicone has been investigated in order to enhance resistance towards certain chemicals and for water tightness $[9,10,11]$. Barlow shows that SLS manufactured molds can also be used for injection molding processes for a limited number of cycles [12]. The company EOS $\mathrm{GmbH}$, Krailling has established the term of DirectPattern when using SLS molds for die casting rubber shoe soles [2].

Vacuum casting is a firmly established rapidprototyping and reproduction process $[13,14]$. In order to reproduce the contour of a part, it is placed into a container with curing silicone. In the next step the developed cavity is die casted with curable resin, for example Polyurethane [2]. The resulting parts reveal an increased reproduction accuracy of surface details from the original part. However, the complexity of the manufacturable contour of such a reproduction process is limited. Up to a certain aspect ratio undercuts can be demolded using elastomeric casting materials. Furthermore, the processable materials need to be pourable and either curable or solidifying. Vacuum is needed in order to prevent any gas enclosures inside the part which could reduce the part's mechanical properties. The achievable accuracy is in a range of $+/-0.3$ $-0.6 \%$ of the nominal dimension [15]. The reproduction quantity using one mold lays between 15 and 30 parts [2, 16]. Using vacuum die casting with a silicone mold and 
laser sintered geometries is often used for rapid manufacturing of parts made from polyurethane [17]. Sometimes, stereolithography (SLA) is used for manufacturing molds either for vacuum casting silicone parts or for injection molding processes $[14,18,19]$.

In comparison to injection molded parts SLS parts display an increased surface roughness due to their powder based manufacturing method [2]. The surface roughness is strongly depending on the positioning of the part in the SLS machine [2, 3]. However, silicone does not show adhesion to most other materials which makes it feasible for direct die casting processes [20].

\section{Motivation}

For many medical applications the material selection is limited to certain approved and certified medical grades. Thus, silicone provides excellent non-reactive and sterile properties as they are needed for applications, such as implants. In order to enable the production of complex shaped parts with curable elastomeric polymers, even more complex shaped molds are necessary.

In this paper a new rapid prototyping process for manufacturing elastomeric parts is investigated by using the Selective Laser Sintering process combined with vacuum die casting. As the surface roughness of laser sintered parts is fairly high, the influence on the demolding process of elastomeric parts shall be analyzed. Thus, the adhesions to the mold, as well as the influence of different release agents on the demolding process are investigated. Furthermore, the mechanical properties of such manufactured silicone parts are compared to the raw material.

Eventually propositions for best results in manufacturing silicone parts using this rapid technology are given.

\section{Methodology ANd Materials}

The rapid manufacturing process consists of two steps; first, the cast design and its manufacturing using the SLS process and secondary the vacuum casting process using two component silicones.

Two specimens are designed, one for testing the resulting mechanical properties and one for investigating the adhesion force between the silicone and the PA12 mold.

A shoulder tensile bar according to DIN 53504 is used to test the elastomeric material on tensile strength, Fig 2. This geometry is used to design a two-pieces mold including a riser tube for the later pouring process and a venting opening. Besides testing the mechanical properties of the resulting silicone parts the vacuum casting process itself shall be investigated using this specimen.

The second specimen is designed with respect to the pull-off test according to DIN 53531 part 2, Fig. 3. It resembles the implementation of demolding a flat silicone part out of a SLS mold. It consists of two notched cylinders with a diameter of $25 \mathrm{~mm}$ which fit into the openings of the mold and later act as mountings for the testing machine. Because the positioning angle influences the surface roughness specimens with two different positioning angles in the SLS machine $\left(0^{\circ}, 60^{\circ}\right)$ are manufactured.

Both specimen molds are manufactured in the SLS process using a Sinterstation 2000 from the company 3DSystems/ formerly DTM, Rock Hill, SC, USA. The mold material is PA12, type PA2200 from the company EOS $\mathrm{GmbH}$, Krailling with a refreshing rate of $50 \%$ related to its mass. In table I the parameters for the SLS process are summarized.

Six tensile bar molds and 36 pull-off specimens are manufactured. In a post process all laser sintered parts are manually blasted using glass balls with a diameter between 150 and $250 \mu \mathrm{m}$ and with a distance of $50 \mathrm{~mm}$ to the part at an approximate angle of $45^{\circ}$.

For the vacuum casting three silicone rubber materials from the company PolyConform $\mathrm{GmbH}$, Düsseldorf, with different viscosity were chosen as shown in table II.

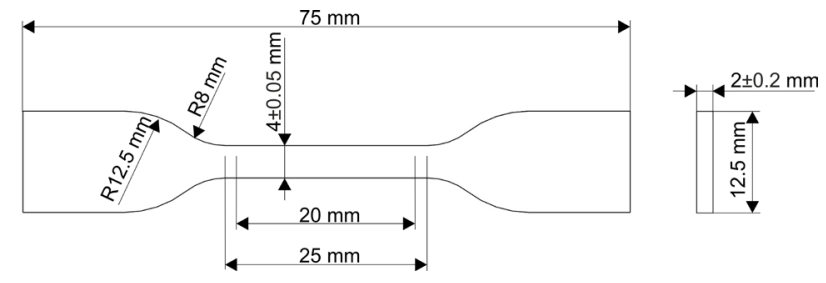

Figure 2. Shoulder Tensile Bar S2 for testing Elastomers.

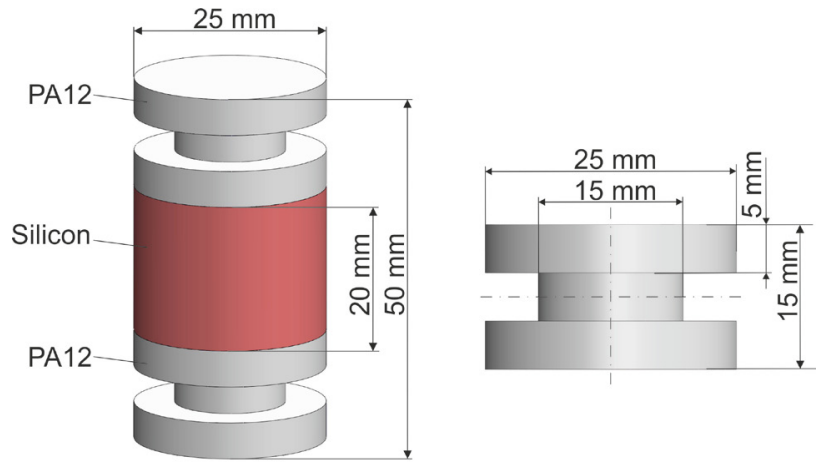

Figure 3. Schematic of the pull-off specimen consisting of two SLS mountings and the inner silicone part.

TABLE I.

PARAMETERS FOR THE SLS PROCESS

\begin{tabular}{|l|c|c|}
\hline Parameter & Unit & Value \\
\hline Laser Power & $\mathrm{W}$ & 4.0 \\
\hline Hatch Distance & $\mathrm{mm}$ & 0.15 \\
\hline Layer Thickness & $\mathrm{mm}$ & 0.1 \\
\hline Scan Speed & $\mathrm{mm} / \mathrm{s}$ & 1257 \\
\hline Energy Volume Density & $\mathrm{J} / \mathrm{mm}^{3}$ & 0.21 \\
\hline Feeder Temperature & ${ }^{\circ} \mathrm{C}$ & 80 \\
\hline CylinderTemperature & ${ }^{\circ} \mathrm{C}$ & 160 \\
\hline Building Platform Temp. & ${ }^{\circ} \mathrm{C}$ & 130 \\
\hline Powder Surface Temp. & ${ }^{\circ} \mathrm{C}$ & 175 \\
\hline Warm-up Phase & $\mathrm{mm}$ & 10 \\
\hline Cooling-Phase & $\mathrm{mm}$ & 2.54 \\
\hline Powder Feed Height & $\mathrm{mm}$ & 0,2 \\
\hline
\end{tabular}

TABLE II.

USED SILICONES WITH DIFFERENT VISCOSITY (*INFORMATION GIVEN BY SUPPLIER)

\begin{tabular}{|l|l|c|}
\hline Material & Name & Viscosity [mPas] \\
\hline Silicone 1 & PlatSILITA 4-18H & $1800^{*}$ \\
\hline Silicone 2 & PlatSILITA 13-45H & $4500^{*}$ \\
\hline Silicone 3 & PlatSILITA 30-45H & $6500^{*}$ \\
\hline
\end{tabular}


The silicone materials are two component silicones which start crosslinking by mixing its components with a ratio of 1:1. In order to avoid air enclosures and to develop a laminar flow inside the cavity a riser is added to the construction of the tensile bar mold. For the vacuum casting three different approaches for the cavity filling are investigated:

A. The silicone is poured into the mold. The complete runner system stays open

B. Same procedure as in A is used with sealing off the runner system in order to use only the porous SLS material to extract any gases out the cavity.

C. The silicone mixture is first evacuated and subsequently poured into the mold using a syringe.

After filling, all molds are closed tight and placed in a vacuum chamber at 50 mbar and cured for at least 24 hours.

Fig. 4 shows the SLS tensile bar mold with the filled silicone and the riser tube.

For each silicone material one SLS mold and six tensile bars are manufactured and tested using a universal testing machine type 1465 by Zwick GmbH \& Co. KG, Ulm. The tensile bars are tested with a preload of $0.05 \mathrm{~N}$ and a traverse speed of $200 \mathrm{~mm} / \mathrm{min}$.

Fig. 5 depicts the pull-off specimen with the opened mold in the background. The SLS mold consists of two semi cylindrical parts with an opening on two sides, a pouring and de-airing opening. The tongues fit into the notches of the pull-off specimen.

Although silicone materials do not show adhesion behaviors on most other materials a mechanical adhesion due to the increased surface roughness of the SLS parts can occur. In order to investigate the adhesion of the manufactured parts to the mold the surface roughness of the SLS parts are measured using a Hommel Tester T1000 wave from the company Jenoptik AG, Jena. Three test lines are measured on the surfaces of the pull-off specimen. Furthermore, two different release agents are tested in combination with different manufacturing angles of the SLS parts using the pull-off specimens. The release agents must not contain any silicon, in order to prevent the inhibitation of the vulcanization process. Furthermore, when using the manufactured parts for medical applications it is important to use biocompatible release agents and therefore wax spray and petrolatum are chosen.

The pull-off test is conducted using a tensile pulling tester according to DIN 51221 , part 3 at a speed of 5 $\mathrm{mm} / \mathrm{min}$. It is important to ensure a concentrical setup and to avoid bending forces on the specimen. Fig. 6 depicts the principle of the pull-off test.

\section{RESUlts}

The manufactured tensile bars with varied filling procedure using silicone 1 are shown in Fig. 7. It can be seen that the quality of the parts vary according to the filling procedure. Pouring the silicone into the cavity and subsequently placing the non-sealed mold into the vacuum chamber leads to a vast amount of air bubbles inside the tensile bar. Some of the silicone material has been pushed out the cavity when the gas enclosures expand inside the

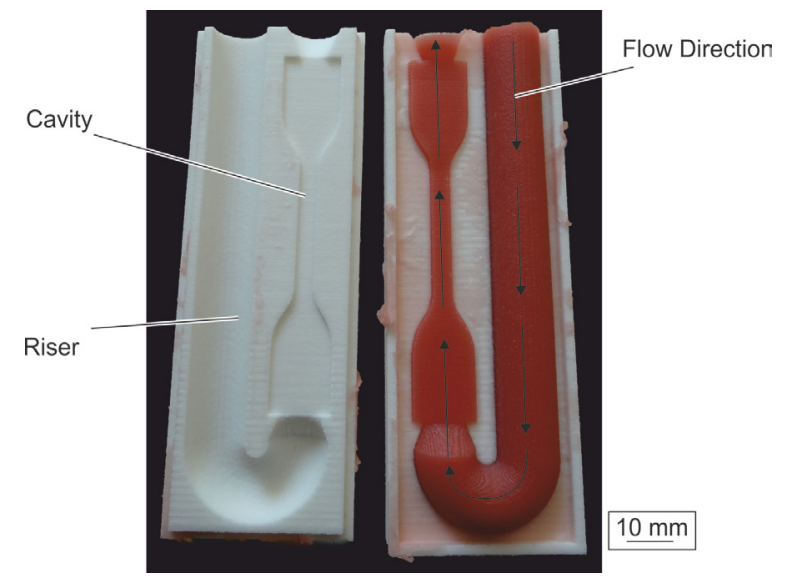

Figure 4. SLS die cast mold for the tensile bar with vertical riser tube.

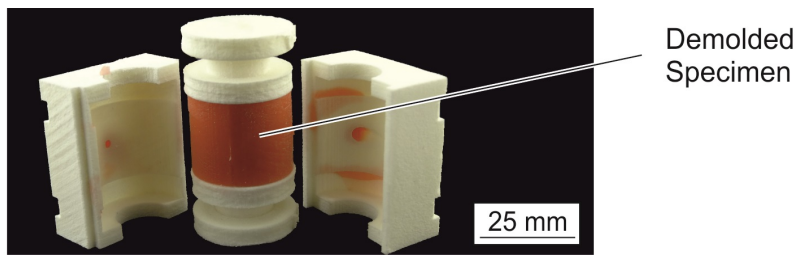

Figure 5. SLS die cast mold for the pull-off specimen.

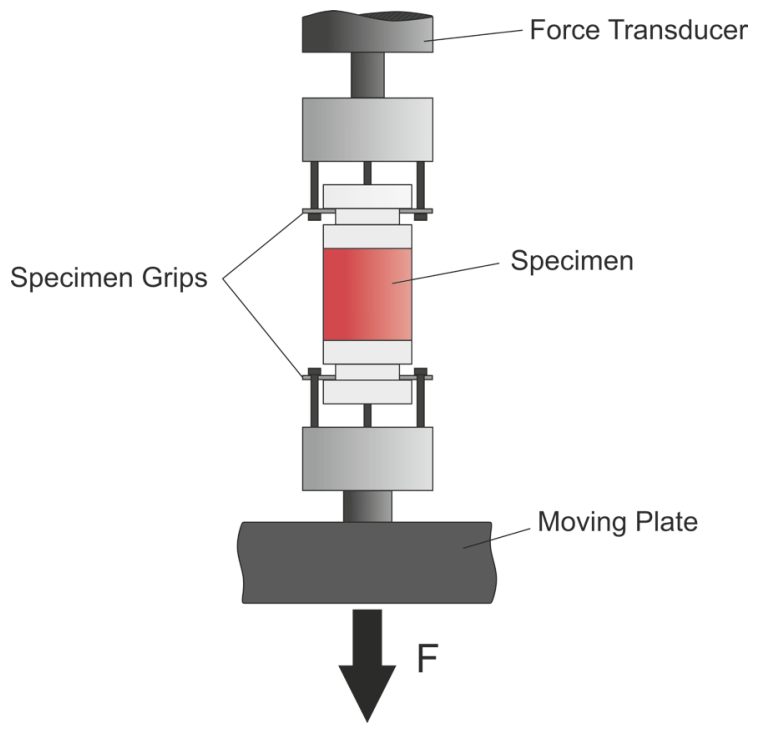

Figure 6. Principle of the pull-off test

vacuum chamber, Fig. 7 a). In contrast, the sealed runner system displays a more compact silicone material b). However, large cavities have developed in both shoulders and the narrow part. Thus, the extraction of the air from the cavity only through the porous SLS material is non feasible. By degassing the silicone mixture first using the vacuum chamber and subsequently using a syringe to fill the mold leads to the best results c). There are no enclosures inside of the part. All following specimens were manufactured using procedure c).

Due to the low viscosity, silicone 1 was the only material being able to pour into the mold. For the other two silicones it was necessary to develop a certain pressure using a syringe. This procedure is used for all further molding processes. It was observed that with increasing viscosity the time for deairing the silicone mixture increases. 
The manufactured tensile bars with the three different silicone materials were tested on mechanical properties. Fig. 8 displays the stress over elongation graph for the three different silicone materials. With increasing elongation the strain rises for all materials. In correlation with a rising viscosity the Young's-modulus increases as well.

In comparison to the material data given by the supplier, the strain at break of the molded parts is approximately $50 \%$, as shown in Fig. 9.

The significantly lowered yield stress may be caused by the increased surface roughness from the mold and the resulting notching effect.

The resulting specimens depict that silicone provides a very detailed mapping of the mold surface. Therefore, the silicone parts are fairly rough and a potential oversize can be observed, compare Fig. 10.

Consecutively the results from the pull-off tests are displayed. The adhesion force between silicone and SLS PA12 mainly results from a mechanical undercut and therefore it is directly depending on the surface roughness.

An average $R_{z}$ roughness for $0^{\circ}$ positioning angle lays at $88 \mu \mathrm{m}$ and for $60^{\circ}$ angle at $139 \mu \mathrm{m}$, Fig. 11 .

When demolding without release agent it can be seen that on the one hand particles from the red silicone stick to the SLS-part, which is originally white colored. On the other hand PA12 particles remain at the silicone as well, Fig. 12.

All petrolatum coated parts couldn't be tested on pulloff force because the parts were departing when demolding. It obviously fills the roughness deepenings and therefore does not allow a mechanical adhesion as shown in Fig. 13.

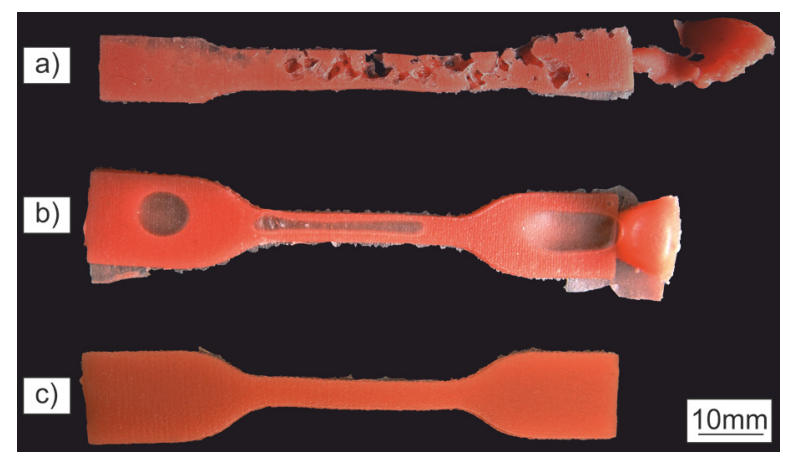

Figure 7. Silicone tensile bars using die cast procedure with a) open runner, b) sealed runner and c) open runner and pre degassed silicone mixture.

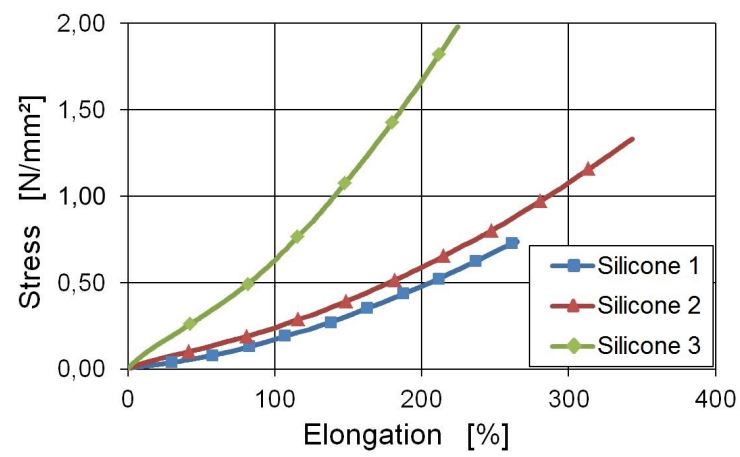

Figure 8. Comparison of the stress - elongation curve for the silicone tensile bars.

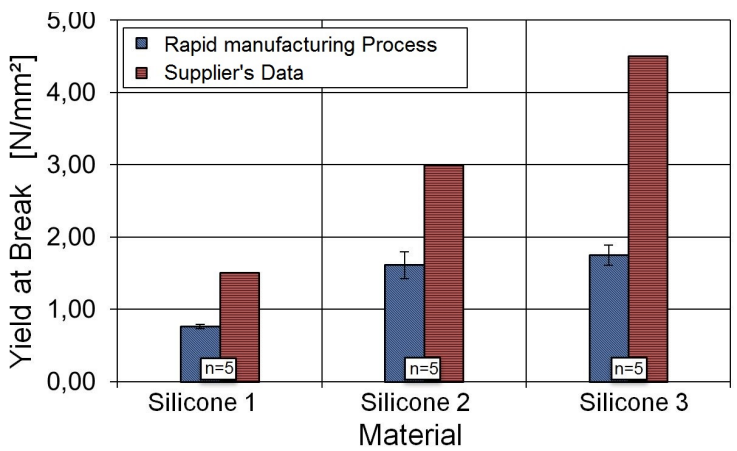

Figure 9. Comparison of the strain break of the manufactured silicone tensile bars compared to supplier information.
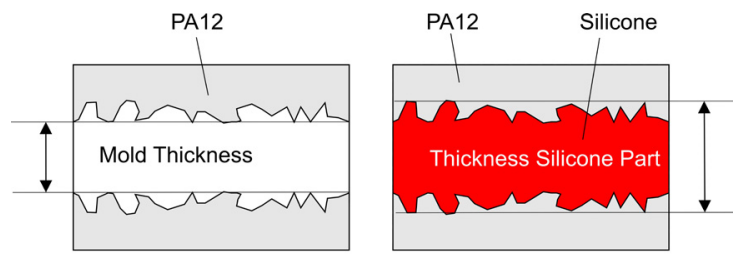

Thickness Mold < Thickness Silicone Part

PA12 Mold

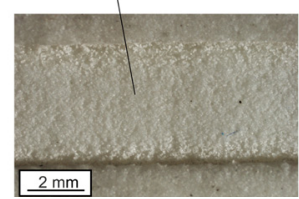

Silicone Part Overmold (Flash)

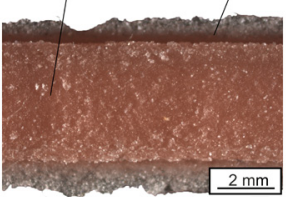

Figure 10. Schematic of the mold surface and the resulting dimensional accuracy of the silicone part.

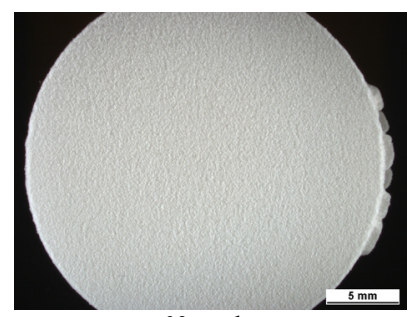

$0^{\circ}$ angle

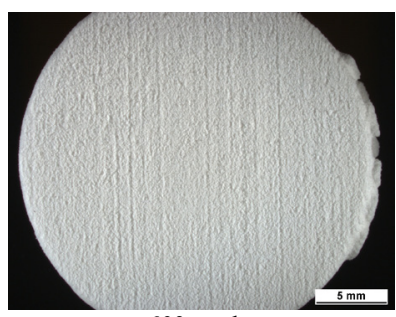

$60^{\circ}$ angle
Figure 11. Comparison of the SLS surface roughness at two different angles.

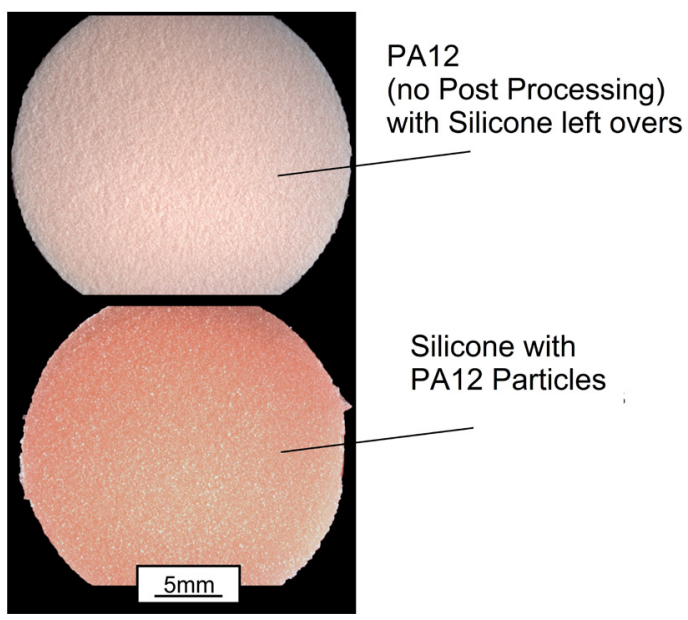

Figure 12. Remaining particles after removing the silicone from the PA12 mold. 
The general setup of the pull-off test is shown in Fig. 14. Moreover, a significant lateral contraction of the silicone can be detected which leads to a peeling effect at the edges before yielding.

Fig. 15 shows exemplarily the force-elongation behavior during the pull-off test for the three different silicones and a building angle of the SLS parts at $60^{\circ}$. While the more flexible silicone 1 shows a peeling before yielding the stiffer silicone 3 suddenly loses adhesion. The adhesion force for silicone 1 is $29.8 \mathrm{~N}$, for silicone $297.9 \mathrm{~N}$ and for silicone $3154.0 \mathrm{~N}$.

The bonding strength for the different silicones, positioning angle of $0^{\circ}$ and $60^{\circ}$, for wax release agent and without release agent are presented in Fig. 16.

Silicone 3 with the highest viscosity shows the highest bonding strength for all angles and release agents. The parts with the applied release agent wax spray already yielded when applying the preload.

The necking of the silicone part also deforms the force lines and results in a multi-axis stress state. This promotes the release of the bonding. The more flexible a silicone, the greater the change in shape and the greater the disturbance forces which lead to break up. This theory is consistent with the results achieved in the pull-off test and shows that this effect predominates in comparison to an advanced inflow of low viscous silicone into the pores and roughness deepenings.

\section{CONCLUSION AND FUTURE WORK}

The combination of the SLS process for manufacturing molds with the vacuum casting technique provides the possibility of extending the material spectrum for manufacturing complex parts for medical applications.

Using a die casting technique with SLS molds and a sufficient vacuum treatment of the mixture first silicone parts were manufactured.

Due to the increased surface roughness and the resulting notching effect the manufactured tensile bars show a significantly lower strain at break compared to the compact material as given in the supplier's data. In order to enhance the mechanical part properties it is necessary to optimize the mold surface.

The resulting bonding strength through pull-off tests are significantly lower than the strains observed during the tensile test, such that the silicone parts are not damaged when demolding.

Petrolatum presents best release properties such that no force was needed to demold the silicone from the SLSparts. Wax spray shows smaller release properties than petrolatum. When dismissing a release agent and using inherent increased surface roughness of the SLS part built at an angle of $60^{\circ}$ an adhesion force up to $154 \mathrm{~N}$ was detected which could be used for two component parts consisting of a stiff SLS material and a flexible silicone material.

In future work it shall be investigated by which portion the surface roughness and therefore the adhesion properties can be determined by varying SLS parameters and by using different post processing techniques. Furthermore, the usage of complex SLS parts acting as lost core for investment casting shall be investigated in order to manufacture nearly hollow components.

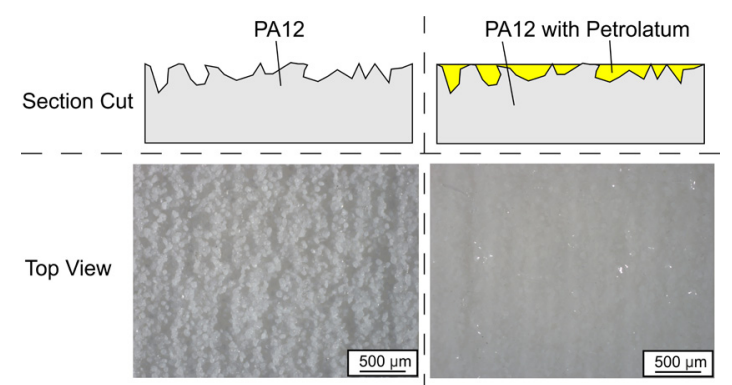

Figure 13. Effect of the release agent petrolatum on the SLS surface.

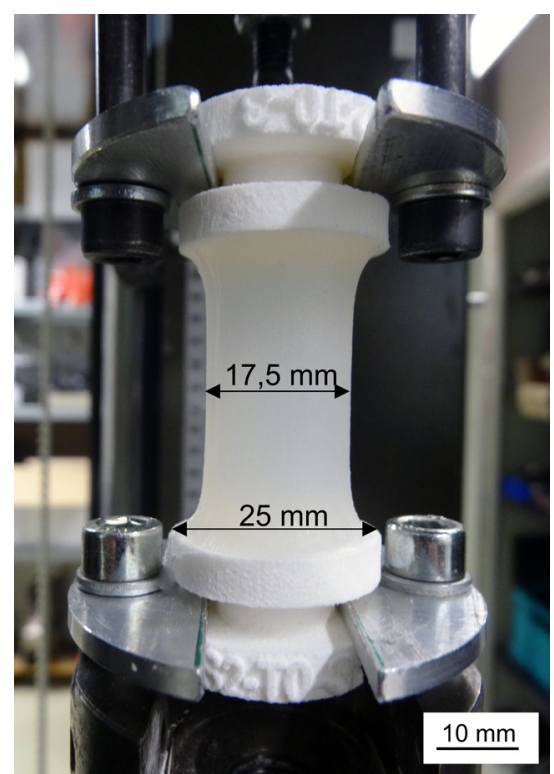

Figure 14. Mounted pull-off specimen during the test.

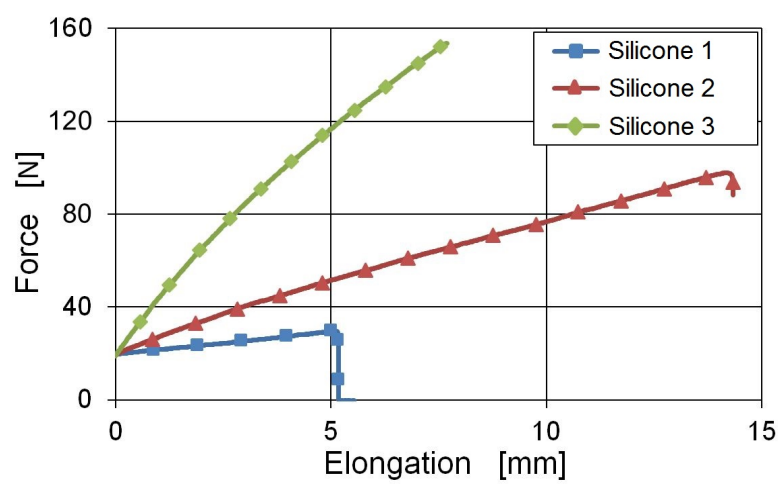

Figure 15. Comparison for the pull-off tests using three different silicones, at $60^{\circ}$ building angle and without release agent.

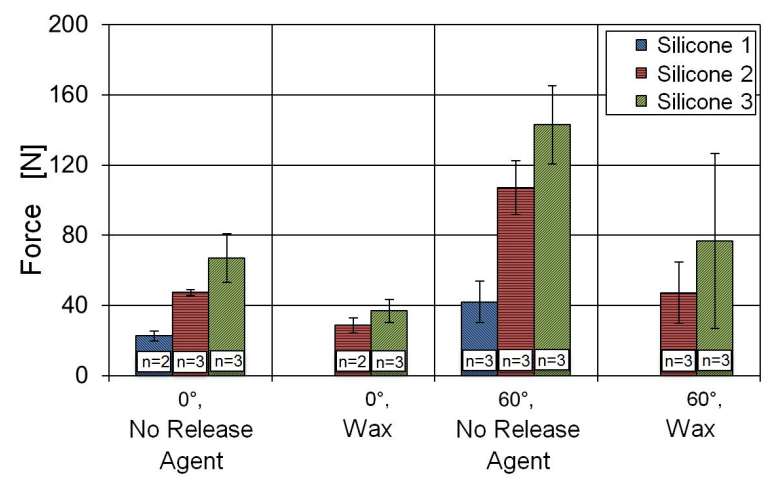

Figure 16. Comparison of the different adhesion coefficients for pulloff specimen at different angle and varying release agent. 


\section{ACKNOWLEDGMENT}

The Authors would like to thank the technicians, students and colleagues at the LKT for the support of conducting experiments. Special thanks belong to the Master Student Peter Appel who has put all his effort and creativity into the development of significant experimental setups.

\section{REFERENCES}

[1] J. Breuninger, R. Becker, A. Wolf, et. al. "Generative Fertigung mit Kunststoffen - Konzeption und Konstruktion für Selektives Lasersintern“, Springer Vieweg, Berlin, 2012.

[2] A. Gebhardt, J.S. Hötter, M. Fateri, "Generative Fertigungsverfahren“, 4. Auflage., Carl-Hanser-Verlag, München, 2007.

[3] W. Kaddar, "Die generative Fertigung mittels Laser-Sintern: Scanstrategien, Einflüsse verschiedener Prozess-parameter auf die mechanischen und optischen Eigenschaften beim LS von Thermoplasten und deren Nachbearbeitungsmöglichkeiten“, Diss-ertation, Universität Duisburg-Essen, 2010.

[4] D. Rietzel, "Werkstoffverhalten und Prozessanalyse beim LaserSintern von Thermoplasten", Dissertation, Friedrich-Alexander Universität Erlangen-Nürnberg, 2011.

[5] Bayer AG $\left(2015\right.$, February, 12 $\left.2^{\text {th }}\right)$. Desmosint $\AA$, Maßgeschneidertes TPU für selektives Lasersintern [Online]. Available: http://www.tpu.bayer.com/de/Products/Desmosint.aspx

[6] J.-P. Kruth, G. Levy, R. Schindel, et. al., "Consolidation of Polymer Powders by Selective Laser Sintering", CIRP Annals - Manufacturing Technology, 56 (2) (2007), pp. 730-759

[7] Fraunhofer, UMSICHT (2015, February, $12^{\text {th }}$ ). TPU Generative, Polyurethane for selective Laser Sintering (SLS) [Online]. Available: http://www.umsicht.fraunhofer.de

[8] Plastics Technology (2015, February, $\left.12^{\text {th }}\right)$. TPU Powders for SLS Prototyping \& Manufacturing [Online]. Available: http://www.ptonline.com/articles/tpu-powders-for-sls-prototypingmanufacturing

[9] M. Schmid, F. Woellecke, G.N. Levy, "Long-Term Durability of SLS Polymer Components under Automotive Application Environment", 23rd Annual International Solid Freeform Fabrication Symposium, Austin, TX, USA, 2012

[10] M. Schmid, C. Simon, G.N. Levy, "Finishing of SLS-parts for rapid manufacturing (RM) - A comprehensive approach", 20th
Annual International Solid Freeform Fabrication Symposium, Austin, TX, USA, 2009.

[11] H. Domininghaus, "Die Kunststoffe und ihre Eigenschaften", 2. Auflage, VDI-Verlag, Düsseldorf, 1986.

[12] J.W. Barlow, J.J. Beaman, B. Balasubramanian, "A rapid mouldmaking system: Material properties and design considerations", 2. Auflage, VDI-Verlag, Düsseldorf, 1986.

[13] M.F. Zäh, "Wirtschaftliche Fertigung mit Rapid-Technologien: Anwender-Leitfaden zur Auswahl geeigneter Verfahren", CarlHanser-Verlag, München, 2013.

[14] C. K. Chua, K. F. Leong, "Rapid Prototyping: Principle and Application in Manufacturing", pp. 212-214, John Wiley, 1997.

[15] A. Kalweit, A. Paul, S. Peters, et al., „Handbuch für Technisches Produktdesign, Material und Fertigung, Entscheidungsgrundlagen für Designer und Ingenieure“, Springer-Verlag, Berlin, Heidelberg 2012. http://dx.doi.org/10.1007/978-3-642-02642-3

[16] J. Bast, B. Awiszus, H. Dürr, et al., "Grundlagen der Fertigungstechnik", Carl-Hanser-Verlage, München, 2009.

[17] C. K. Chua, S. M. Chou, S. C. Lin, et al., "Facial prosthetic model fabrication using rapid prototyping tools", Emerald Insight, Vol. 11 Issue 1, pp. $42-53,2000$.

[18] C. K. Chua, T. H. Chew, K. H. Eu, "Integrating Rapid Prototyping and Tooling with Vacuum Casting for Connectors", The International Journal of Advanced Manufacturing Technology, SpringerVerlag London, 1998.

[19] T. H. Chew, C. K. Chua, H. S. Ong, "Rapid Moulding Using Epoxy Tooling Resin“, The International Journal of Advanced Manufacturing Technology, Springer-Verlag London, 2002.

[20] Wacker Chemie AG (2015, February, $\left.12^{\text {th }}\right)$. Silicone, Verbindungen und Eigenschaften. [Online]. Available: http://www.wacker.com/cms/media/publications/downloads/6415 DE.pdf

\section{AUTHORS}

M. Launhardt, M. Drexler and D. Drummer are with Friedrich-Alexander-Universität Erlangen-Nürnberg (FAU), Institute of Polymer Technology (LKT), Erlangen, Germany.

Submitted 09 April 2015. Published as resubmitted by the authors 12 May 2015. 